\title{
- Toracoscopia em equiinos: estudo comparativo entre duas técnicas de abordagem
}

\section{- Thoracoscopy in horses: comparison between two approach techniques}

\author{
* André Luis do Valle De Zoppa ${ }^{1}$-CRMV-SP- n $^{0} 10149$ \\ Luis Cláudio Lopes Correia daSilva ${ }^{2}$ - CRMV-SP- n ${ }^{0} 5993$ \\ Joséde Alvarenga ${ }^{3}$ - CRMV-SP - $n^{0} 0132$ \\ Denise Tabacchi Fantoni ${ }^{4}$ - CRMV-SP-n ${ }^{0} 5625$ \\ ${ }^{1}$ Mestre em Cirurgia pelo Departamento de Cirurgia da FMVZ - USP/SP. \\ 2 Professor Doutor do Departamento de Cirurgia da FMVZ - USP/SP. \\ ${ }^{3}$ Professor Titular Aposentado do Departamento de Cirurgia da FMVZ - USP/SP. \\ ${ }_{4}^{4}$ Professora Livre Docente do Departamento de Cirurgia da FMVZ - USP/SP.
}

\section{RESUMO}

A toracoscopia tem sido cada vez mais indicada como exame auxiliar para diagnóstico das diversas afecções do tórax. Com o objetivo de comparar duas técnicas de abordagem para inspeção da cavidade pleural, foram utilizados 16 animais hígidos, que foram submetidos à toracoscopia, dos quais dez sob anestesia geral com intubação orobronquial seletiva e seis em posição quadrupedal sob sedação associada à anestesia local. Foram abordados os hemitórax direito e esquerdo, com intervalo de 15 dias entre cada procedimento. Durante a abordagem, pôde-se observar as diversas estruturas da cavidade torácica, a saber: músculo diafragma (porção muscular e tendínea), hiato esofágico, mediastino, artéria aorta, troncos dorsal e ventral do nervo vago, ducto torácico, veia ázigos, veias intercostais, músculos intercostais, costelas, tronco nervoso simpático, tronco vascular toracocervical, traquéia, pulmão (lobo cranial e caudal), esôfago, pericárdio, veia cava caudal, nervo frênico, linfonodos aórticos. A realização do exame toracoscópico com os animais sedados e mantidos em posição quadrupedal possibilitou a identificação de um maior número de estruturas. A toracoscopia mostrou ser exame de grande auxílio, pela facilidade e rapidez de execução e ampla inspeção da cavidade pleural, mas a escolha de posicionamento do animal irá depender do órgão ou estrutura a ser preferencialmente abordada. Nos casos em que se optar pelo decúbito, há que se considerar o emprego da ventilação mecânica com intubação orobronquial seletiva.

Palavras-chave: toracoscopia, endoscopia, tórax, pleura, eqüinos.

\section{Introdução e Revisão de Literatura}

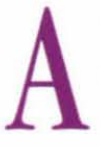

toracoscopia foi introduzida por Jacobeus, em seres humanos, em 1910 como método diagnóstico das afecções que acometem a cavidade pleural.

De acordo com GINSBERG (1993) apud VACHON e FISCHER (1998), a toracoscopia tem sido empregada em seres humanos para o diagnóstico e tratamento de afecções da pleura, pulmão, mediastino, grandes vasos, pericárdio e esôfago.

A toracoscopia pode ser praticada por meio de endoscópio rígido ou flexível e é indicada quando outros exames de auxílio diagnóstico das afecções da cavidade torácica, como ultra-sonografia, radiografia e biopsia percutânea não tiverem efetivos, uma vez que a toracosco- 
pia é técnica invasiva e necessita de anestesia geral ou sedação profunda do paciente para que possa ser realizada (HINCHCLIFF e BYRNE, 1991). Sua principal vantagem está na inspeção direta das estruturas do tórax, observação de aderências, realização de biopsias de lesões torácicas ou aspiração de fluidos, possibilitando diagnóstico mais preciso, que não tenha sido possível com auxílio de outros exames complementares (ROSSIER et al., 1990; BEECH, 1991; HINCHCLIFF e BYRNE, 1991). As estruturas que podem ser observadas pela toracoscopia em eqüinos são: coração, pericárdio, artéria aorta, diafragma, lobos pulmonares, incisura cardíaca, vasos mediastinais, veia ázigos, esôfago, costelas, vasos e musculatura intercostal (MANSMANN e BERNARDSTROTHER, 1985; POTTER E HENDRICKSON, 1999), timo (POTTER e HENDRICKSON, 1999) e tronco dorsal e ventral do nervo vago, ducto torácico, tronco simpático, tronco toracocervical, traquéia, veia cava caudal (DE ZOPPA et al., 1998).

Dentre as indicações mais freqüentes para a utilização da toracoscopia podemos citar: avaliações em casos de pleuropneumonia (MANSMANN e BERNARD-STROTHER, 1985; BYARS e BECHT, 1991), neoplasia intratorácica, presença de aderência, metástase, pericardite, abscesso pulmonar e coccidiomicose (MACKEY e WHEAT, 1985; McCARTHY e McDERMAID, 1990; FREEMAN, 1991; POTTER e HENDRICKSON, 1999). Outras indicações para a toracoscopia incluem biopsia pulmonar e pleural (BENISAAC e SIMMONS, 1975; HENDRICKSON e WILSON, 1996; POTTER e HENDRICKSON, 1999), diagnóstico de derrame pleural (HATCH e DeCAMP, 1966), pleuris bacteriana (POTTER e HENDRICKSON, 1999), hérnia diafragmática (POTTER e HENDRICKSON, 1999), avaliação de corpos estranhos e observação de fístulas broncopleurais (BYARS e BECHT, 1991), diagnóstico de hemangiossarcoma (BEECH, 1991), colocação de drenos (VACHON e FISCHER, 1998) e drenagem de abscessos (HENDRICKSON e WILSON, 1996; POTTER e HENDRICKSON, 1999).

A esterilização do equipamento pode ser feita prls imersão em soluções bactericidas, como iodopovidine a $10 \%$, por uma hora (MANSMANN e BERNARDSTROTHER, 1985) ou glutaraldeído por 20 minutos (MACKEY e WHEAT, 1985); posteriormente, deve-se enxaguar o material com solução salina esterilizada.

Quanto à anestesia, ao posicionamento do animal, ao local de acesso torácico e à conduta pós-operatória, têm sido várias as técnicas de toracoscopia descritas em eqüinos.
A técnica de toracoscopia pode ser realizada com o animal em posição quadrupedal, com anestesia local, associada, quando necessário, a sedativos e analgésicos (MACKEY e WHEAT, 1985; MANSMANN e BERNARD-STROTHER, 1985; FORD et al., 1987; FREEMAN, 1991). A dose recomendada de cloridrato de xilazina associada a butorfanol é de respectivamente 0,55 $0,85 \mathrm{mg} / \mathrm{kg}$ e $0,01 \mathrm{mg} / \mathrm{kg}$, ambos por via intravenosa (IV) (FORD et al., 1987; FREEMAN, 1991).

De acordo com POTTER e HENDRICKSON (1999), a toracoscopia pode ser realizada com o animal sedado com cloridrato de xilazina na dose de $0,5 \mathrm{mg} / \mathrm{kg}$ ou detomidina na dose de $0,02 \mathrm{mg} / \mathrm{kg}$, ambas por via intravenosa, associadas ou não ao tartarato de butorfanol na dose de $0,05 \mathrm{mg} / \mathrm{kg}$.

A ventilação com oxigênio (15 l/min), em procedimentos com o animal em posição quadrupedal quando este apresentava sinais de descompensação cardiorrespiratória, foi citada por VACHON e FISCHER (1998).

A realização do procedimento com o paciente sob anestesia geral foi citada como viável por MACKEY e WHEAT (1985), porém não há relato da técnica. VACHON e FISCHER (1998) utilizaram anestesia geral nos casos de pleuropneumonia com necrose de lobo pulmonar, pericardite séptica, hemiplegia laringeana bilateral e hérnia diafragmática com estrangulamento do intestino delgado, seguindo o seguinte protocolo: indução com cloridrato de xilazina $(1,1 \mathrm{mg} / \mathrm{kg}, \mathrm{IV})$, diazepam $(0,01 \mathrm{mg} /$ $\mathrm{kg}$, IV) e cloridrato de quetamina (3 mg/kg, IV), manutenção com halotano vaporizado em oxigênio e ventilação controlada com pressão positiva.

De acordo com McCARTHY e McDERMAID (1990), a opção pela anestesia geral irá depender do estado de higidez do animal e tipo de afecção presente. Segundo os autores, avaliação pré-anestésica, incluindo hemograma completo, urinálise, radiografia pulmonar, eletrocardiograma, toracocentese e ultra-sonografia, dará subsídios para diminuir o risco da anestesia, o que também é citado por POTTER e HENDRICKSON (1999). $\mathrm{O}$ paciente indicado para ser submetido à toracoscopia é deixado em jejum por doze horas e segue protocolo anestésico para cirurgias torácicas. $\mathrm{O}$ animal é intubado com sonda orotraqueal e mantido durante o procedimento em respiração com pressão positiva (McCARTHY e McDERMAID, 1990).

POTTER e HENDRICKSON (1999) relataram que a anestesia geral deve ser utilizada quando a ventilação controlada for necessária ou quando se realiza toracoscopia em ambos hemitórax num mesmo procedimento. Segundo VACHON e FISCHER (1998), a utilização 
da técnica de ventilação orobronquial seletiva pode ser aplicada em cavalos submetidos à toracoscopia, melhorando as trocas gasosas nesses animais.

A escolha do posicionamento do animal em decúbito lateral ou dorsal dependerá do acesso desejado e da localização da lesão (VACHON e FISCHER, 1998).

A escolha do espaço intercostal para realização do procedimento depende do local de suspeita da lesão, sendo indicado que se faça abordagem o mais próximo possível da lesão. A porção caudal do mediastino é melhor observada pelo $10^{\circ}$ espaço intercostal, enquanto a maior parte da superfície pulmonar é observada através do $8^{\circ}$ espaço intercostal (POTTER e HENDRICKSON, 1999). VACHON e FISCHER (1998) relataram que as toracoscopias foram realizadas entre o $8^{\circ}$ e $11^{\circ}$ espaço intercostal, ligeiramente abaixo da inserção do músculo trapézio.

O acesso torácico para introdução do endoscópio, segundo MACKEY e WHEAT (1985); POTTER e HENDRICKSON (1999) é feito através de incisão de aproximadamente $2 \mathrm{~cm}$ em pele e tecido subcutâneo; os músculos intercostais são divulsionados, a pleura é perfurada com pinça hemostática, e uma tentacânula é passada para o interior da cavidade pleural. A passagem da tentacânula através da pleura parietal deve ser feita de maneira cuidadosa para se evitar punção ou laceração do tecido pulmonar (MANSMANN e BERNARDSTROTHER, 1985).

Após a retirada do endoscópio, o ar presente no interior do tórax pode ser drenado com aspirador cirúrgico, evitando-se, assim, a ocorrência de intenso pneumotórax residual que possa acarretar alterações respiratórias (POTTER e HENDRICKSON, 1999). Esta manobra de drenagem pode ser acompanhada visualmente antes da retirada do endoscópio (MANSMANN e BERNARDSTROTHER, 1985). Após a drenagem do ar presente na cavidade pleural, a musculatura intercostal é suturada com fio não absorvível, utilizando-se ponto simples separado ou ponto em " $X$ ". A pele é suturada com fio não absorvível e ponto em " $\mathrm{X}$ " (POTTER e HENDRICKSON, 1999).

Segundo MACKEY e WHEAT (1985), a toracoscopia pode ser praticada várias vezes, desde que se respeite o intervalo de dois dias entre o exame de cada hemitórax. VACHON e FISCHER (1998) relataram que exames consecutivos de ambos hemitórax foram realizados em nove eqüinos, que toleraram bem os procedimentos, contrariando o trabalho anteriormente citado.

\footnotetext{
1 Sedivet ${ }^{\circledR}$ - Boehringer Ingelheim

2 Diazepan ${ }^{\circledR}$ - Cristália

3 Ketamina Agener® - Agener

4 Halothano $^{\circledR}$ - Cristália
}

As possíveis complicações da prática de toracoscopia, segundo MACKEY e WHEAT (1985); MANSMANN E BERNARD-STROTHER (1985); POTTER e HENDRICKSON (1999), são infecção, pneumotórax, lacerações pulmonares e dor.

Segundo POTTER e HENDRICKSON (1999), a utilização de antibióticos e antiinflamatórios não esteróides é determinada pelo cirurgião, na dependência da lesão observada no tórax. A utilização de antibioticoterapia (22.000 UI/ $\mathrm{kg}$ de penicilina procaina, intramuscular) e analgésico $(4,4 \mathrm{mg} / \mathrm{kg}$ de fenilbutazona, IV), a cada doze horas por dois dias é recomendado por ROSSIER et al. (1990).

\section{Material e Método}

Foram utilizados dezesseis eqüinos hígidos, de peso, sexo, raça e idade variados, provenientes do Departamento de Cirurgia da F.M.V.Z. - USP, realizando-se 20 procedimentos em 10 animais submetidos à anestesia geral com intubação orobronquial seletiva e 12 procedimentos em seis animais mantidos em posição quadrupedal e submetidos à sedação, associada à anestesia local. Os animais selecionados foram submetidos a dois procedimentos de toracoscopia, um em cada hemitórax (esquerdo e direito), com intervalo mínimo de 15 dias.

Anteriormente ao procedimento toracoscópico, os animais foram submetidos a exame clínico pré-operatório, pelo qual foram avaliados os seguintes parâmetros: freqüência cardíaca, freqüência respiratória, temperatura corpórea, coloração de mucosas, auscultação cárdiopulmonar, hemograma e fibrinogênio plasmático.

Para cada exame, foi empregada a abordagem no $13^{\circ}$ espaço intercostal, por onde se realizou avaliação minuciosa das porções ventral, dorsal, cranial e caudal da cavidade pleural.

Para os dez animais que foram submetidos à toracoscopia em decúbito lateral (Grupo I), utilizou-se o seguinte protocolo anestésico: após jejum alimentar de 12 horas e hídrico de 4 horas, administrou-se romifidina ${ }^{1}$ na dose de $0,12 \mathrm{mg} / \mathrm{kg}$ por via intravenosa (I.V.); após 15 minutos, o paciente foi induzido com diazepan ${ }^{2}(0,05 \mathrm{mg} /$ $\mathrm{kg} \mathrm{IV})$, seguido de cloridrato de quetamina ${ }^{3}(2,0 \mathrm{mg} / \mathrm{kg}$ IV). Com o animal em decúbito lateral, foi realizada intubação orotraqueal e manutenção da anestesia com halotano $^{4}$ vaporizado em oxigênio $100 \%$. O animal foi colocado em ventilação controlada, com volume corrente de $15 \mathrm{ml} / \mathrm{kg}$ e pressão positiva no final da expiração (PEEP) de $5 \mathrm{~cm}$ de água, sendo a frequiência respiratória mantida em torno de 10 a 12 movimentos respiratórios por minuto. A intubação orobronquial foi efetuada após estabiliza- 


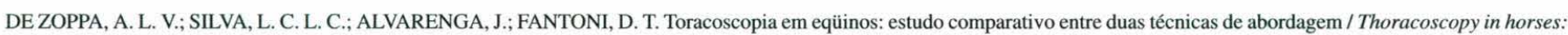
comparison between two approach techniques. / Rev. educ. contin. CRMV-SP / Continuous Education Journal CRMV-SP, São Paulo, volume 4, fascículo 2, p. 16 - 23, 2001.

ção da anestesia. Nesse momento houve a substituição da sonda orotraqueal pela orobronquial. A intubação com a sonda orobronquial foi auxiliada pela passagem de um vídeo-endoscópio ${ }^{5}$ em seu interior, possibilitando identificação visual dos brônquios.

Para os seis animais que foram submetidos à toracoscopia em posição quadrupedal (Grupo II), utilizou-se o seguinte protocolo: após jejum alimentar e hídrico de 12 horas, administrou-se romifidina na dose de $0,12 \mathrm{mg} / \mathrm{Kg}$ por via intravenosa, precedida de meperidina ${ }^{6}$ na dose de $1,0 \mathrm{mg} / \mathrm{Kg}$ por via intramuscular. O paciente foi mantido em tronco de contenção durante todo o procedimento.

A esterilização do fibroscópio ${ }^{7}$ foi realizada, deixando-o submerso em solução anti-séptica à base de polioctil-poliamino-etilglicina e polioxietileno-alquil-fenol-éter ${ }^{8}$ por 30 minutos e, posteriormente, enxaguado com solução fisiológica esterilizada.

Incisão de aproximadamente dois centímetros foi realizada na pele, seguida de incisão e divulsão romba da musculatura intercostal. Com o uso de pinça hemostática de Crile, a pleura parietal foi perfurada, permitindo a formação de pneumotórax. Ato contínuo, foi introduzido o trocarte ${ }^{9}$, pelo interior do qual se passou o fibroscópio acoplado a microcâmera ${ }^{10}$ em direção à cavidade pleural.

Durante a exploração da cavidade pleural, foram observados o aspecto e posicionamento das estruturas anatômicas e, no decorrer do procedimento, o animal foi reavaliado clinicamente.

Após a finalização do exame, o ar intratorácico foi aspirado através do próprio fibroscópio. Concomitante a esse procedimento, para os animais submetidos à anestesia geral, a sonda orobronquial foi recuada para a traquéia, recuperando a ventilação nos dois pulmões. Tal manobra objetivou diminuir ao máximo a ocorrência de pneumotórax no período pós-operatório. Seguido da retirada da cânula e do endoscópio, a musculatura foi suturada em ponto contínuo festonado, com fio de náilon $\mathrm{n}^{\circ} 2.0^{11}$, e a pele suturada em pontos simples separados, com fio de náilon $n^{\circ} 2.0$, sendo aplicado curativo e bandagem protetora no local.

Os animais receberam acompanhamento pós-operatório seguindo-se protocolo predeter-

\footnotetext{
5 Vídeo-gastroscópio flexível para eqüinos

KARL STÖRZ, modelo NOVA

6 Dolantina ${ }^{\circledR}$ - Hoechst do Brasil.

7 Endoscópio OLYMPUS, modelo GIF-XQ20

8 Obanol $516^{\circledR}$ - Fatec S. A

9 Trocarte ETHICON, modelo Endopath $10 / 11 \mathrm{~mm}$

10 Vídeo-câmera KARL STÖRZ, modelo Telecam-C Pal

11 Superlon 2-0 $0^{\circledR}$ - Cirumédica
}

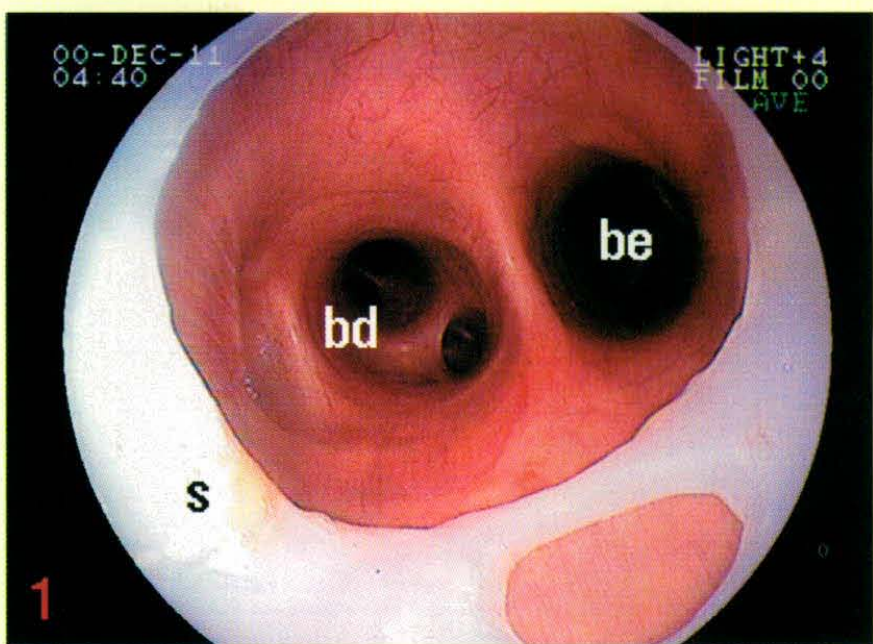

Figura 1. Imagem endoscópica da região da carina de eqüino submetido à intubação orobronquial seletiva. Nota-se: bd: brônquio direito; be: brônquio esquerdo; s: sonda orobronquial.

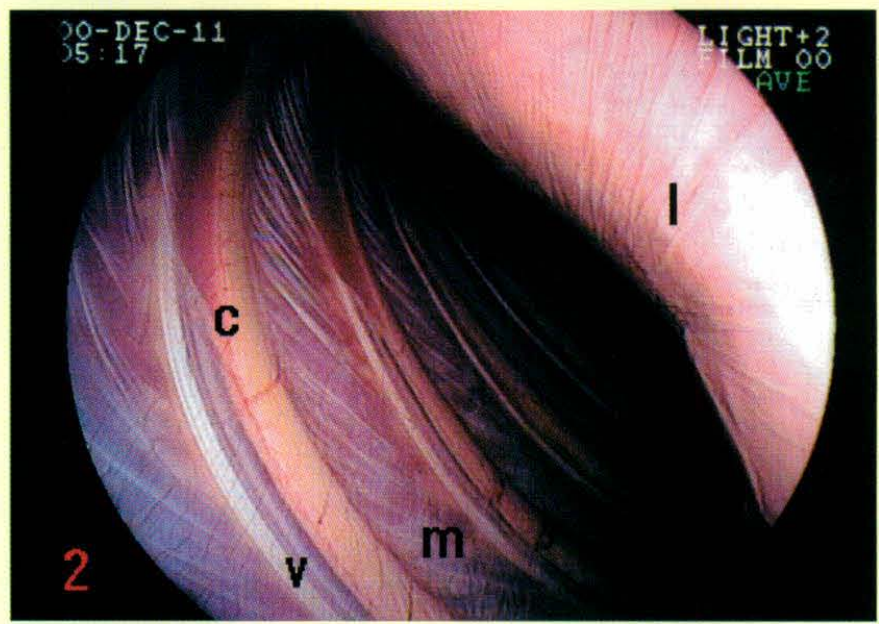

Figura 2. Fotografia do hemitórax esquerdo de eqüino submetido à toracoscopia com fibroscópio flexível. Nota-se: c: costelas; m: musculatura intercostal; v: vasos intercostais; l: lobo pulmonar.

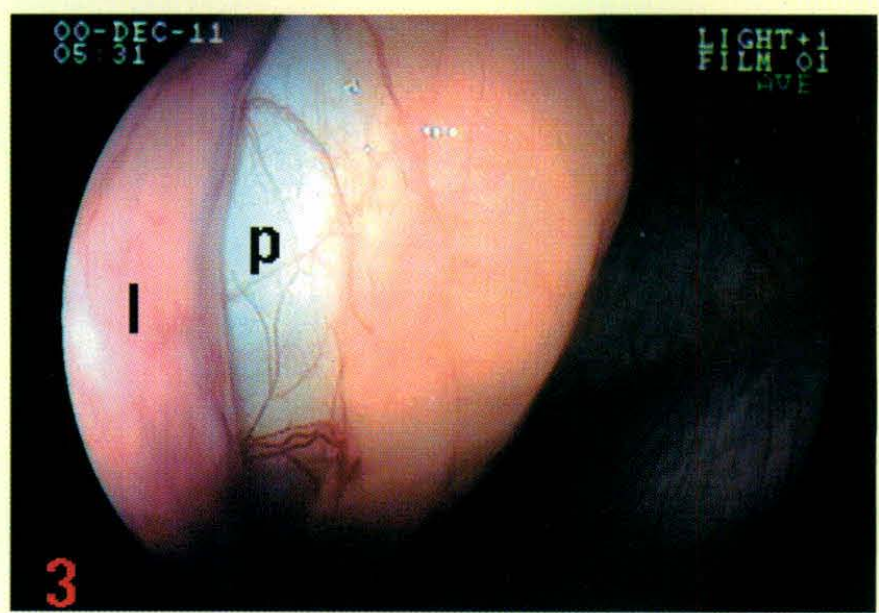

Figura 3. Fotografia do hemitórax esquerdo de eqüino submetido à toracoscopia com fibroscópio flexível. Nota-se: p: pericárdio; l: lobo pulmonar. 


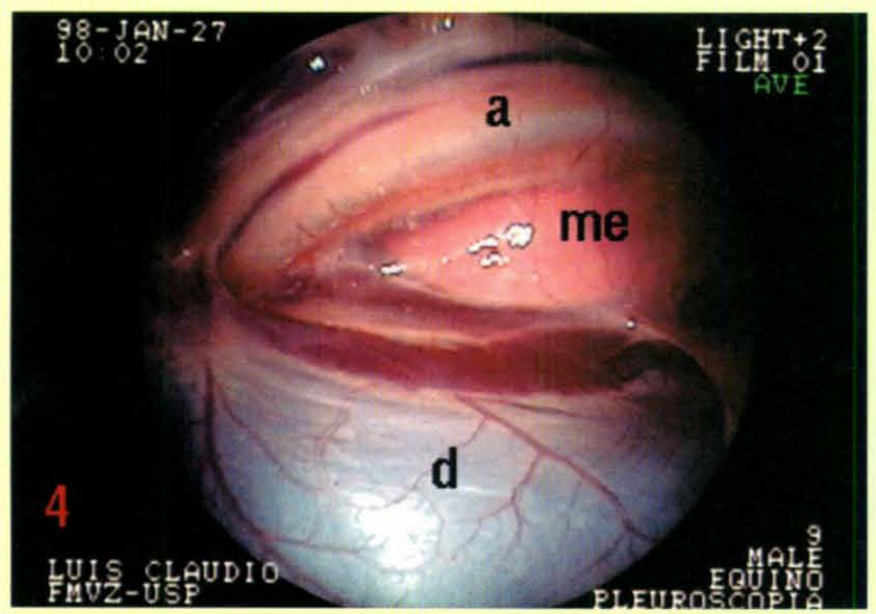

Figura 4. Fotografia do hemitórax direito de eqüino submetido à toracoscopia com fibroscópio flexível. Nota-se: d: diafragma (porção muscular e tendínea); me: mediastino; a: artéria aorta.

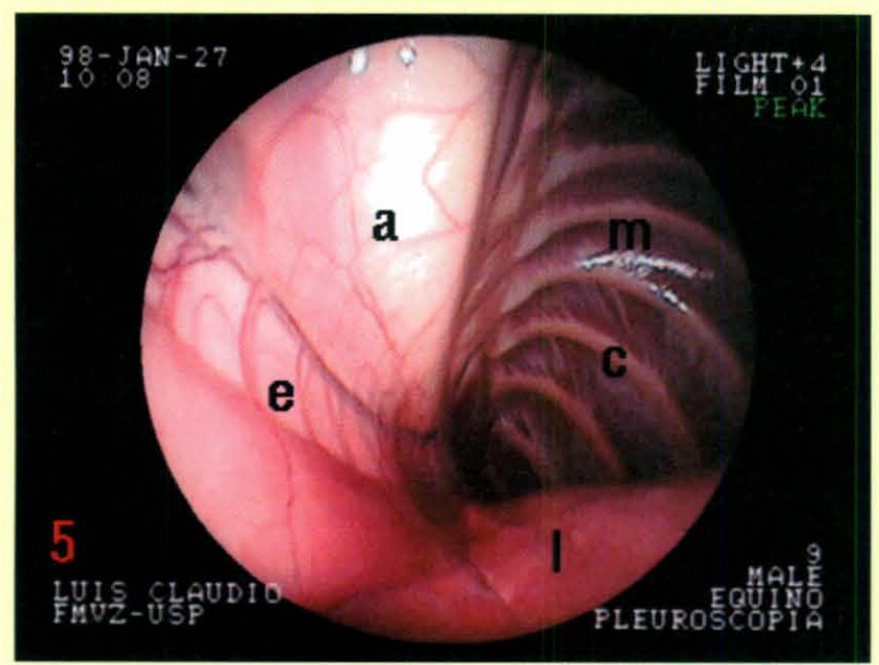

Figura 5. Fotografia do hemitórax direito de eqüino submetido à toracoscopia com fibroscópio flexível. Nota-se: c: costelas; m: musculatura intercostal; I: lobo pulmonar; a: aorta; e: esôfago

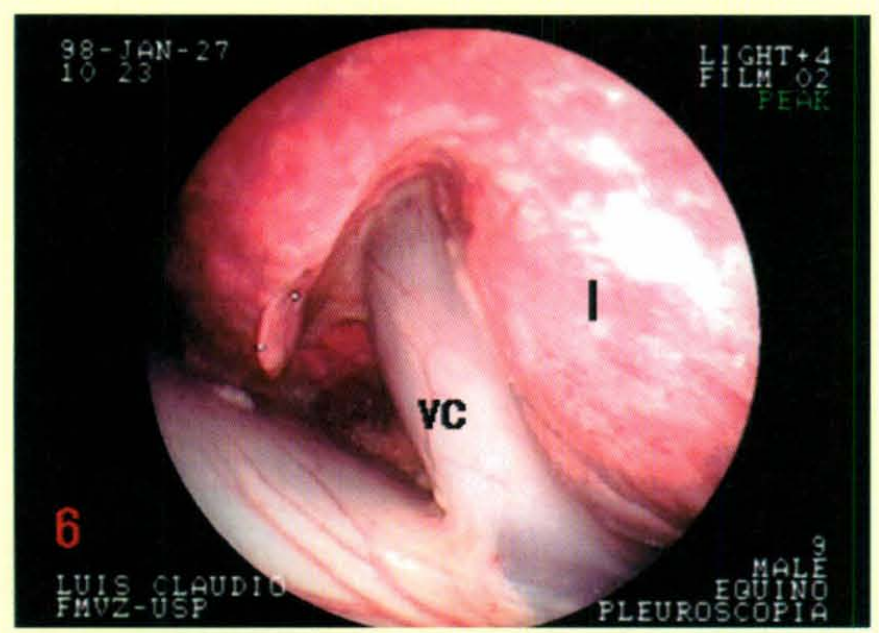

Figura 6. Fotografia do hemitórax direito de eqüino submetido à toracoscopia com fibroscópio flexível. Nota-se: vc: veia cava caudal; l: lobo pulmonar. minado: exame físico por auscultação cardíaca e pulmonar, mensuração da temperatura retal e avaliação da coloração das mucosas no período pós-operatório imediato e, a partir desse momento, a cada $24 \mathrm{~h}$ até o décimo dia; coleta de sangue para hemograma e dosagem de fibrinogênio plasmático 24,72 e $144 \mathrm{~h}$ após o procedimento; curativo diário da ferida cirúrgica até sua cicatrização e retirada dos pontos no $10^{\circ}$ dia; administração de fenilbutazona ${ }^{12}$ na dose de $2,0 \mathrm{mg} / \mathrm{kg}$ a cada $24 \mathrm{~h}$, durante 3 dias.

\section{Resultados}

\section{Grupo I}

A realização da intubação orobronquial seletiva foi facilitada pela presença do gastroscópio no interior da sonda orobronquial, desde a sua introdução na cavidade oral do animal até o momento em que o manguito foi inflado (Figura 1).

A escolha do $13^{\circ}$ espaço intercostal não permitiu a realização do exame toracoscópico em apenas um animal, devida à presença do músculo diafragma próximo à parede torácica, o que lhe levou à punção e necessidade de abordagem pelo $11^{\circ}$ espaço intercostal.

A perfuração da pleura parietal com pinça hemostática de Crile permitiu a indução gradativa do pneumotórax e tornou mais segura a passagem do trocarte, não ocorrendo laceração de tecido pulmonar.

O posicionamento dos animais em decúbito lateral permitiu a visibilização das seguintes estruturas: costelas, musculatura e vasos intercostais, pulmão (Figura 2), pericárdio (Figura 3).

A aspiração do ar do interior da cavidade torácica foi realizada com o próprio endoscópio acoplado a aspirador cirúrgico, que permitiu o acompanhamento da expansão pulmonar e seu conseqüente reposicionamento dentro da cavidade torácica.

Ocorreu deiscência dos pontos de pele, apenas em um animal e foi observada a formação de enfisema subcutâneo em dois animais, após apresentarem episódios de tosse.

No exame físico dos animais, apesar de aos valores da freqüência respiratória, freqüência cardíaca e temperatura retal apresentarem variações,

\footnotetext{
12 Equipalazone ${ }^{\circledR}$ - Marcolab
} 


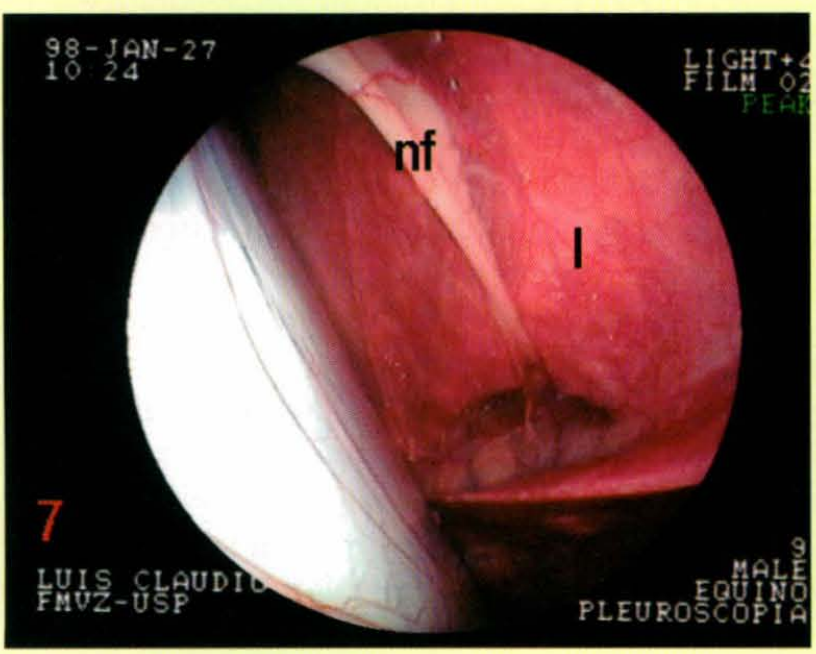

Figura 7. Fotografia do hemitórax direito de eqüino submetido à toracoscopia com fibroscópio flexível. Nota-se: nf: nervo frênico; l: lobo pulmonar.

não ultrapassaram o intervalo de normalidade, tampouco foram observados sinais clínicos que demonstrassem qualquer desconforto dos animais. O hemograma e fibrinogênio plasmático não apresentaram alterações estatisticamente significativas.

\section{Grupo II}

O protocolo anestésico utilizado conferiu boa sedação e analgesia e em todos os animais, a freqüência cardíaca permaneceu dentro da faixa de normalidade.

A perfuração da pleura parietal foi feita com pinça hemostática de Crile, sendo o pneumotórax provocado lentamente através da sua abertura. Durante a formação do pneumotórax, nenhum animal apresentou sinais de descompensação, sendo apenas observado aumento na freqüência e amplitude respiratória dos animais.

Seguindo a seqüência preestabelecida para inspeção da cavidade pleural, foi possível observar as seguintes estruturas:

a) Hemitórax direito: porção muscular e tendínea do diafragma, hiato esofágico, mediastino, artéria aorta (Figura 4), tronco dorsal e ventral do nervo vago, ducto torácico, veia ázigos, veias intercostais, músculos intercostais, costelas (Figura 5), tronco simpático, tronco toracocervical, traquéia, pulmão (lobo cranial e caudal), esôfago, pericárdio, veia cava caudal (Figura 6) e nervo frênico (Figura 7);

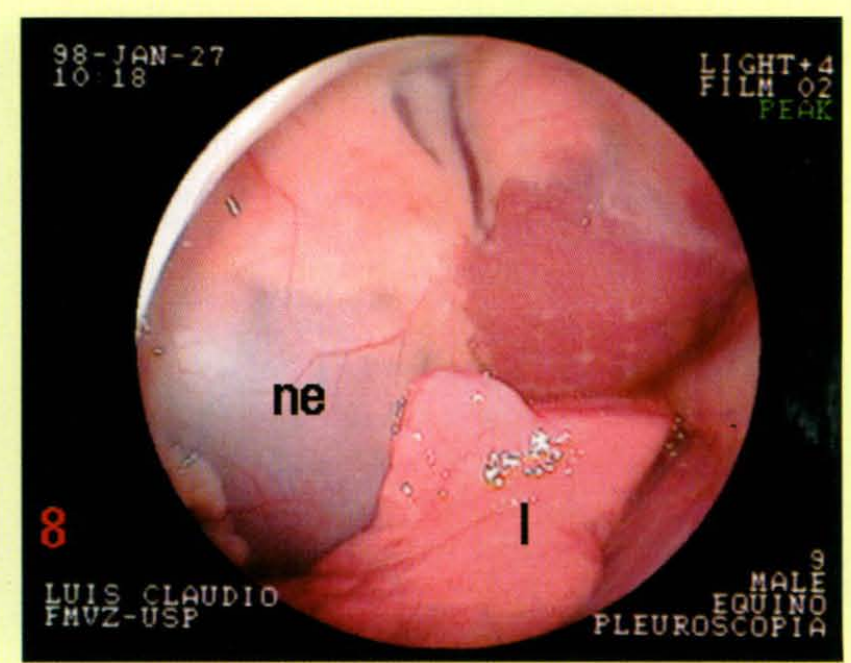

Figura 8. Fotografia do hemitórax esquerdo de equiino submetido à toracoscopia com fibroscópio flexível. Nota-se: pe: pericárdio; l: lobo pulmonar.

b) Hemitórax esquerdo: diafragma, hiato esofágico, mediastino, artéria aorta, tronco dorsal e ventral do nervo vago, linfonodos aórticos, veias intercostais, músculos intercostais, costelas, tronco simpático, tronco toracocervical, nervo frênico, esôfago, pulmão (lobo cranial e caudal) e pericárdio (Figura 8).

Durante o procedimento, um animal apresentou tosse, o que levou, como conseqüência, à formação de enfisema subcutâneo, não causando qualquer limitação para o prosseguimento do exame.

Durante a aspiração do ar intratorácico, observou-se melhora da respiração, detectada pela diminuição na freqüência e amplitude respiratória (MD F.R. no procedimento: 23,67 mrm e no pós-operatório imediato: $12,17 \mathrm{mrm}$ ), mas, que após o término da aspiração e sutura da musculatura intercostal, houve retorno da freqüência respiratória a valores basais (MD: 15,67 $\mathrm{mrm})$. Os resultados obtidos através dos exames físicos no acompanhamento pós-operatório não foram acompanhados de alterações clínicas dos animais.

Em relação ao hemograma e ao fibrinogênio plasmático, não foram observados valores que ultrapassassem os intervalos de normalidade.

\section{Discussão}

Por ser procedimento invasivo que, em muitas situações, requer que o animal seja submetido à anestesia geral, estamos de acordo com HINCHCLIFF e BYRNE (1991) quanto à indicação da toracoscopia apenas nos 
casos em que métodos de diagnóstico, não invasivos, foram infrutíferos ou inconclusivos.

A possibilidade de inspeção de toda a cavidade torácica torna a toracoscopia um exame com numerosas indicações, como as citadas por ROSSIER et al. (1990); BEECH (1991); BYARS e BECHT (1991); HINCHCLIFF e BYRNE (1991); VACHON e FISCHER (1998).

A exemplo do indicado por BEN-ISAAC e SIMMONS (1975), a escolha do fibroscópio flexível baseou-se no fato de esse modelo de endoscópio nos possibilitar manobras mais amplas, incrementando a área de inspeção da cavidade torácica, facilitando a visibilização de estruturas mais craniais.

A realização da técnica de intubação orobronquial com o auxílio de endoscópio flexível (gastroscópio de eqüino), passado por dentro da sonda, possibilitou-nos a utilização de sondas de comprimentos adequados, não havendo a necessidade de realização de traqueostomia. O procedimento de intubação orobronquial foi realizado da maneira mais rápida possível, não ultrapassando o tempo de dois minutos e 30 segundos, limite para que um eqüino possa ficar em apnéia. Foi observado o cuidado de aprofundar a anestesia e hiperventilar o animal, possibilitando, dessa maneira, a troca da sonda orotraqueal pela orobronquial de modo seguro.

A utilização do $13^{\circ}$ espaço intercostal permitiu observar as estruturas da cavidade pleural, quando dos animais em posição quadrupedal. Contrariamente, nos animais posicionados em decúbito lateral e submetidos à anestesia geral, a escolha desse espaço intercostal, resultou na impossibilidade de visibilização dos hiatos aórtico e esofágico.

O posicionamento dos animais em decúbito lateral resultou na não observação dos vasos mediastinais e esôfago, já que, nesse decúbito, o pulmão acaba por recobrir essas estruturas. Sugerimos que para a inspeção dessas estruturas seja escolhido um acesso cirúrgico mais cranial ou a manutenção do animal em posição quadrupedal. Havendo a necessidade de manter esses animais em anestesia com ventilação mecânica e de acessar estruturas como esôfago torácico, sugerimos que os pacientes sejam mantidos em decúbito esternal e não lateral, o que acreditamos facilitaria o acesso de tal estrutura.

A incisão de pele em dois centímetros a exemplo do citado por MACKEY e WHEAT (1985), superior à necessária para a introdução do trocarte visou à eliminação do ar expelido durante a respiração ou episódios de tosse, impedindo seu acúmulo no subcutâneo, o que provoca enfisema.

Concordamos com MANSMANN e BERNARDSTROTHER (1985), quando eles citam que a passagem do trocarte pela pleura parietal deve ser feita de maneira cuidadosa para se evitar laceração ou punção de tecido pulmonar, fato que não ocorreu durante a realização dos 32 procedimentos deste experimento.

Após o exame da cavidade torácica, o ar foi aspirado, assim como foi citado por MACKEY e WHEAT (1985); FREEMAN (1991); HENDRICKSON e WILSON (1996); POTTER e HENDRICKSON (1999). A utilização da aspiração foi imprescindível para que não persistisse intenso pneumotórax residual após a retirada do endoscópio e do trocarte. Nos animais submetidos a anestesia geral, com o mesmo intuito, e concomitantemente à aspiração do ar intratorácico, a sonda orobronquial foi tracionada para a região da carina, permitindo expansão pulmonar gradativa.

\section{Conclusão}

Tendo em vista a dificuldade em se diagnosticar algumas afecções da cavidade torácica e com o intuito de apressar esse diagnóstico, a técnica de toracoscopia mostrou-se viável, segura e rápida; a utilização do endoscópio flexível facilitou o acesso a grande parte das estruturas da cavidade torácica.

A realização da toracoscopia com os animais sob sedação em posição quadrupedal, possibilitou a visibilização de um maior número de estruturas da cavidade torácica em relação aos animais submetidos à anestesia geral. Nos casos em que se optar pelo decúbito, há que se considerar o emprego da ventilação mecânica com intubação orobronquial seletiva. 


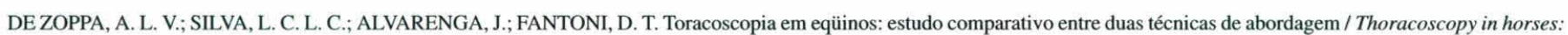
comparison between two approach techniques. / Rev. educ. contin. CRMV-SP / Continuous Education Journal CRMV-SP, São Paulo, volume 4, fascículo 2, p. 16 - 23, 2001.

\section{SUMMARY}

Thoracoscopy has been used more frequently as an ancillary exam in the diagnosis of several thoracic diseases. In order to compare two approach techniques to inspect the pleural cavity, sixteen healthy animals underwent thoracoscopy. Ten horses received general anesthesia with selective orobronchial intubation and six were maintained in standing position under sedation associated with local anesthesia. The right and left hemithorax were approached with a fifteen-day interval between each procedure. It was possible to observe the following different structures of the thoracic cavity during the exam: the diaphragm muscle (muscular and tendinous portions), esophageal hiatus, mediastinum, aorta, dorsal and ventral branches of the vagus nerve, thoracic duct, azigus vein, intercostal vessels and muscles, ribs, sympathetic nerve trunk, thoracocervical vascular trunk, trachea, lung (cranial and caudal lobes), esophagus, pericardium, caudal cava vein, phrenic nerve, aortic lymphnodes. A larger number of structures could be identified in standing animals. Thoracoscopy proved to be a very helpful exam, as it is easy to perform. In addition, it is not time-consuming and provides a wide inspection of the pleural cavity. The animal's position will depend on the organ or structure to be examined. When lateral recumbence is chosen, the use of mechanical ventilation with selective orobronchial intubation must be considered.

Key words: thoracoscopy, endoscopy, thorax, pleura, equines.

\section{REFERÊNCIAS}

1. BEECH, J. Thoracocentesis, pleuroscopic examination, and lung biopsy. In: BEECH, J. Equine respiratory disorders. Pensylvania: Lea \& Febiger, 1991. cap. 5, p. 66-67.

2. BEN-ISAAC, F. E.; SIMMONS, D. H. Flexible fiberoptic pleuroscopy: Pleural and Lung Biopsy. Chest, v. 67, n. 5, p. 573$576,1975$.

3. BYARS, T. D.; BECHT J. L. Pleuropneumonia. Veterinary Clinics of North American: Equine Practice, v. 7, n. 1, p. 63$78,1991$.

4. DE ZOPPA, A. L. V.; ALVARENGA, J.; SILVA, L. C. L. C.; MIGLIATTI, E. R.; FERREIRA, M. A. Pleuroscopia em eqüinos: Estudo da técnica e emprego como método de avaliação da cavidade pleural. In: CONGRESSO BRASILEIRO DO COLÉGIO BRASILEIRO DE CIRURGIA E ANESTESIOLOGIA VETERINÁRIA, 3., 1998, Belo Horizonte. Anais... Belo Horizonte: Colégio Brasileiro de Cirurgia e Anestesiologia Veterinária, 1998. p. 161.

5. FORD, T. S.; VAALA, W. E.; SWEENEY, C. R.; SKAND, D.; SAIK, J. E. Pleuroscopic diagnosis of gastroesophageal squamous cell carcinoma in a horse. Journal American Veterinary Medical Association, v. 90, n. 12, p. 1556-1558, 1987.

6. GINSBERG, 1993 apud VACHON, A. N.; FISCHER, A. 1998.

7. FREEMAN, D. E. Pleuroscopy. Veterinary Clinics of North American: Equine Practice, v. 7, n. 3, p. 621-623, 1991.

8. HATCH, H. B.; DeCAMP, P. T. Diagnostic Thoracoscopy. The Surgical Clinics of North America - Thoracic Surgery, v. 46, n. 6, p. 1405-1410, 1966.
9. HENDRICKSON, D. A.; WILSON, D. G. Instrumentation and techniques for Laparoscopic and Thoracoscopic surgery in the horse. Veterinary Clinics of North American: Equine Practice, v. 12, n. 2, p. 235-251, 1996.

10. HINCHCLIFF, K. W.; BYRNE, B. A. Clinical examination of the respiratory system. Veterinary Clinics of North America: Equine Practice, v. 7, n. 1, p. 1-26, 1991.

11. MACKEY, V. S.; WHEAT, J. D. Endoscopic examination of the equine thorax. Equine Veterinary Journal, v. 17, n. 2, p. 140$142,1985$.

12. McCARTHY, R. A.; Mc DERMAID, S. C. Thoracoscopy. Veterinary Clinics of North American: Small Animal Practice, v. 20, n. 5, p. 1341-1353, 1990.

13. MANSMANN, R. A.; BERNARD-STROTHER, S. Pleuroscopy in horses. Modern Veterinary Practice, v. 66, n. 1, p. 9-17, 1985.

14. POTTER, L.; HENDRICKSON, D. A. Therapeutic video-assisted thoracic surgery. In: FREEMAN, L. J. Veterinary endosurgery. St. Louis: Mosby, 1999. cap. 9, p. 188-191.

15. ROSSIER, Y.; SWEENEY, C. R.; HEYER, G.; HAMIR, A. N. Pleuroscopic diagnosis of disseminated hemangiosarcoma in a horse. Journal of the American Veterinary Medical Association, v. 196, n. 10, p. 1639-1640, 1990.

16. VACHON, A. M.; FISCHER, A. Thoracoscopy in the horse: diagnostic and therapeutic indications in 28 cases. Equine Veterinary Journal, v. 30, n. 6, p. 467-475, 1998. 